Artigo

\title{
Pensando de outro modo um tipo de conteúdo proposto pela Educação Matemática Crítica dentro da educação matemática
}

\section{Thinking otherwise a type of content proposed by Critical Mathematics Education within mathematics education}

\section{Pensando de otra manera un tipo de contenido propuesto por Educación Matemática Crítica dentro de la educación matemática}

\author{
Júlio César Gomes de Oliveira ${ }^{1}$ \\ [0000-0002-6535-7428] \\ Marcio Antonio da Silva 2 \\ [0000-0002-5061-8453]
}

\section{Resumo}

Este artigo tem como objetivo analisar uma tecnologia de governo evocada para a efetivação de possíveis posições de sujeito (docentes e discentes) em um currículo-EMC. Recorrendo à análise de discurso foucaultiana, utiliza como corpus especializado de análise trabalhos que foram publicados em revistas da educação matemática e no Encontro Nacional de Educação Matemática $(2010,2013,2016)$. Apresenta como resultado um enunciado construído nas análises: conteúdo enfatiza um trabalho com foco na realidade dos estudantes, destacando problemas relevantes e interessantes que abordam questões sociais. $\mathrm{O}$ estudo conclui que um currículo-EMC cria sua própria tecnologia de governo para produção de sujeitos, por meio do uso de técnicas e procedimentos que são colocados a operar para reforçar o seu próprio discurso. Assim, o enunciado produzido estaria relacionado a uma das técnicas deste campo tecnológico, qual seja, técnica de trabalhar o conteúdo com foco na realidade dos estudantes. São destacados três pontos: (i) nessa técnica, a realidade pensada por um currículo-EMC envolve problemas do cotidiano, de professores e alunos, que possuem aspectos coletivos e não, simplesmente, individuais, (ii) essa técnica faz funcionar uma prática não coercitiva, mas que estabelece relações de poder que propõem um modo de governar sem governar por intermédio de um jogo estratégico entre as liberdades e (iii) essa técnica, também, propõe outras relações de poder como, por exemplo, que estudantes e professores sejam inseridos em um contexto em que a própria matemática adquire status de ciência legitimada e reconhecida como capaz de tratar de problemas reais.

Palavras-chave: Educação Matemática. Educação Matemática Crítica. Currículo de Matemática. Conteúdo. Tecnologia de Governo.

\section{Abstract}

This article aims to analyze a government technology evoked for the realization of possible subject positions (teachers and students) in an CME-curriculum. Using Foucault's discourse analysis, it uses as a specialized corpus of analysis works that were published in mathematics education magazines and

${ }^{1}$ julio.oliveira@ifgoiano.edu.br, Doutor em Educação Matemática pela Universidade Federal de Mato Grosso do Sul (UFMS), Professor do Ensino Básico, Técnico e Tecnológico do Instituto Federal Goiano (IFgoiano), Ipameri/GO, Brasil.

2 marcio.silva@ufms.br, Doutor em Educação Matemática pela Pontifícia Universidade Católica de São Paulo (PUC/SP), Professor do Instituto de Matemática e do Programa de Pós-Graduação em Educação Matemática da Universidade Federal de Mato Grosso do Sul (UFMS), Campo Grande/MS, Brasil. 
in the National Meeting of Mathematical Education (2010, 2013, 2016). As a result, a enunciation constructed in the analysis: content emphasizes a work focused on the reality of the students, highlighting relevant and interesting problems that address social issues. The study concludes that an CME-curriculum creates its own government technology for subject production, through the use of techniques and procedures that are put in place to reinforce its own discourse. Thus, the enunciation produced would be related to one of the techniques in this technological field, namely, the technique of working with content with a focus on the students' reality. Three points are highlighted: (i) in this technique, the reality thought by an CME-curriculum involves everyday problems, of teachers and students, which have collective aspects and not, simply, individual, (ii) this technique works a noncoercive practice, but that establishes power relations that propose a way of governing without governing through a strategic game between freedoms and (iii) this technique also proposes other power relations, such as, for example, that students and teachers are inserted in a context in which mathematics itself acquires legitimate science status and recognized as capable of dealing with real problems.

Keywords: Mathematical Education. Critical Mathematical Education. Mathematics Curriculum. Content. Government Technology.

\section{Resumen}

Este artículo tiene como objetivo analizar una ttecnología del gobierno evocada para la realización de posibles puestos de sujeto (docentes y estudiantes) en un en un currículum-EMC. Utilizando el análisis del discurso de Foucault, utiliza como corpus especializado, trabajos de análisis que se publicaron en revistas de educación matemática y en la Reunión Nacional de Educación Matemática (2010, 2013, 2016). Como resultado, presenta un enunciado construido en el análisis: el contenido enfatiza un trabajo centrado en la realidad de los estudiantes, destacando problemas relevantes e interesantes que abordan cuestiones sociales. El estudio concluye que un curriculum-EMC crea su propia tecnología del gobierno para la producción de sujetos, mediante el uso de técnicas y procedimientos que se implementan para reforzar su propio discurso. Por lo tanto, lo enunciado producido estaría relacionada con una de las técnicas en este campo tecnológico, a saber, la técnica de trabajar con contenido con un enfoque en la realidad de los estudiantes. Se destacan tres puntos: (i) en esta técnica, la realidad pensada por un curriculum-EMC involucra problemas cotidianos, de docentes y estudiantes, que tienen aspectos colectivos y no, simplemente, individuales, (ii) esta técnica hace que una práctica no coercitiva funcione, pero que establece relaciones de poder que proponen una forma de gobernar sin gobernar a través de un juego estratégico entre libertades y (iii) esta técnica también propone otras relaciones de poder, como, por ejemplo, que los estudiantes y los docentes se inserten en un contexto en el que la matemática misma adquiere el estatus de ciencia legítima y se reconoce que es capaz de lidiar con problemas reales.

Palabras claves: Educación Matemática. Educación Matemática Crítica. Currículo de Matemáticas. Contenido. Tecnología del gobierno.

\section{Palavras introdutórias...}

Neste trabalho, assumimos que as próprias pesquisas "são textos curriculares [...], inclusive em educação matemática ${ }^{3}$, já que boa parte das pesquisas se fundamenta em teorias que produzem uma narrativa que prescreve como a educação deveria ser" (SILVA, M.A., 2018,

\footnotetext{
3 Preferimos usar educação matemática e não Educação Matemática (com iniciais maiúsculas) para diferenciar uma perspectiva de pensar a educação matemática como algo em constante construção, como uma política cultural.
} 
p. 11). Diante disso, ao tratar as pesquisas que se envolvem com a Educação Matemática Crítica, em uma abordagem discursiva de inspiração foucaultiana, consideramos que tais estudos constroem um currículo crítico, a que chamaremos de currículo-EMC.

Procuramos colocar em funcionamento um movimento de pesquisa que problematiza o próprio campo da educação matemática como política cultural, na medida em que "toda produção humana e trabalho humano é cultural -, estamos sempre negociando valores, modos de ver e maneiras de entender o mundo" (VALERO, 2018, p. 46). Nessa compreensão, um currículo-EMC produz modos de ver e entender dentro da educação matemática relacionado ao que seria o desejável em termos de professor, aluno, ensino e conteúdo, por exemplo. Dessa forma, esta investigação procura descrever o discurso de um currículo-EMC produzido e reproduzido pela própria pesquisa em educação matemática, focalizando aspectos concernentes a um tipo de conteúdo específico.

Esta pesquisa não tem a intenção de refutar as contribuições de um currículo-EMC dentro da educação matemática, mas é, na perspectiva das pesquisas contemporâneas e para a própria educação matemática, uma atividade que problematiza o que estamos fazendo de nós mesmos nos próprios movimentos estabelecidos na e pela educação matemática. Assim, é imprescindível assumirmos um currículo-EMC diferentemente do que se pensa dentro da educação matemática quando esse propõe um tipo de conteúdo, por exemplo. Esse modo de pensar tem a ver com uma vertente da educação matemática que busca pesquisar a própria pesquisa como geradora de categorias, estabelecendo, a partir dessa ação, aquilo que seria o desejável e o não desejável (VALERO; ANDRADE-MOLINA; MONTECINO, 2015) tanto para um tipo de ensino quanto para um tipo de conteúdo - este último é foco do artigo em questão.

É na compreensão desse modo de pensar que formulamos o objetivo para este estudo, o qual é: analisar uma tecnologia de governo evocada para a efetivação de possíveis posições de sujeito ${ }^{4}$ (docentes e discentes) em um currículo-EMC.

\section{Das ferramentas teórico-metodológicas, composição de um corpus especializado e análise}

[...] nas relações humanas, há todo um conjunto de relações de poder que podem ser exercidas entre os indivíduos, no seio da família, em uma relação pedagógica, no corpo político (FOUCAULT, 2004a, p. 266).

Em uma inspiração foucaultiana, recorremos à noção de tecnologia que está vinculada à "articulação de certas técnicas e de certos tipos de discurso acerca do sujeito" (FOUCAULT, 1993, p. 206). Ao desenvolver seus estudos relacionados ao campo do governo - entendido aqui como um modo de "estruturar o eventual campo de ação dos outros", como "conduzir condutas" (FOUCAULT, 1995, p.244) -, Foucault inicia pelas técnicas de dominação. Por exemplo, aqui podemos pensar na disciplina como um componente vinculado a uma tecnologia de um poder disciplinar que atravessa a escola, o asilo, a prisão e muitos outros setores da sociedade (FOUCAULT, 2014). Ao perceber que o poder consiste em relações

\footnotetext{
${ }^{4}$ Em outros artigos, construímos enunciados destinados a uma posição de aluno desejável OLIVEIRA; SILVA, M.A., 2019b) e de professor desejável (OLIVEIRA; SILVA, M.A., 2019a) dentro da educação matemática que são estabelecidos pela prática discursiva de um currículo-EMC. É nosso interesse, agora, discutir como um currículo-EMC parece criar uma tecnologia de governo para efetivar tais posições desejáveis.
} 
complexas que estão para além de um sistema de coerção, o filósofo estuda as técnicas de $\mathrm{si}^{5}$, por exemplo, a técnica da confissão que, no decorrer de suas análises, adquire nuances completamente diferentes ao longo da história (FOUCAULT, 1993).

Nesse deslocamento de seus estudos, ao comentar sobre três grandes tipos de técnicas (técnicas de produção, técnicas de significação e técnicas de dominação) sugeridas por Habermas, Foucault nos afirma que:

[...] fiquei cada vez mais consciente de que, em todas as sociedades, existem outros tipos de técnicas, técnicas que permitem aos indivíduos efetuarem um certo número de operações sobre os seus corpos, sobre as suas almas, sobre o seu próprio pensamento, sobre a sua própria conduta, e isso de tal maneira a transformarem-se a eles próprios, a modificarem-se, ou a agirem num certo estado de perfeição, de felicidade, de pureza, de poder sobrenatural e assim por diante. Chamemos a estes tipos de técnicas as técnicas ou tecnologias do eu (FOUCAULT, 1993, p. 207, grifo nosso).

A partir desse deslocamento o campo do governo será compreendido pela interação entre as técnicas de dominação e técnicas de si, ou seja, nas palavras de Foucault, "esse contato entre as tecnologias de dominação sobre os outros e as tecnologias de si, eu chamo de governamentalidade" (FOUCAULT, 2004b, p. 324). Para o filósofo, o sujeito seria a dobradiça onde tais técnicas estariam atuando.

Dessa forma, inspirados em Foucault, esta pesquisa propõe pensar um currículo-EMC, em uma abordagem discursiva, como uma forma de poder-saber dentro da educação matemática que busca constituir uma tecnologia de governo a partir de técnicas e procedimentos que procuram direcionar os indivíduos, a fim de que sejam produzidas possíveis subjetividades consideradas desejáveis por este currículo. Em outros termos, uma tecnologia de governo de um currículo-EMC está relacionada às formas de "'aplicar saberpoder', não se tratando somente de técnicas para aprender uma língua ou para fabricar produtos, tal como um automóvel" (BAMPI, 2003, p. 37). Para além disso, essa tecnologia corresponde a

técnicas que produzem modos de falar, de se comportar, de ser e de agir, que supõem ideais e aspirações. Trata-se de um conjunto de operações e procedimentos, vinculados a efeitos locais de poder, que normalizam e instrumentalizam as condutas dos indivíduos e dos grupos (BAMPI, 2003, p. 37-38, grifo nosso).

Uma tecnologia de governo de um currículo-EMC, como "uma matriz de razão prática" (FOUCAULT, 2004b, p. 323), com suas técnicas e procedimentos, que serão apresentados em nossas análises, pode estabelecer relações de poder que estão muito mais ao lado das técnicas de si pensadas por Foucault do que das técnicas de dominação.

Ao considerar tal pensamento sobre técnicas e procedimentos que compõem uma tecnologia de governo de um currículo-EMC, outra questão que assumimos é o fato de as práticas pedagógicas serem pensadas como discurso, entendidas como um "conjunto de

\footnotetext{
${ }^{5}$ Isso pode ser compreendido também como "tecnologias do eu", mas preferimos, neste trabalho, a noção de "tecnologias de si" em vez de "tecnologias do eu" e de "técnicas de si" em vez de "técnicas do eu" por acreditarmos que isso pode gerar um problema da existência de um suposto "eu". Tal problema pode ter sido produzido pelas traduções de alguns textos do filósofo do inglês para o português.
} 
práticas em que se produz ou transforma a experiência que os indivíduos têm de si e que lhes permite constituir-se em sujeitos" (MARÍN-DIAZ; NOGUERA-RAMIREZ, 2014, p. 56).

Diante do exposto, recorremos à análise do discurso, de inspiração foucaultiana, para produzirmos enunciados que estejam relacionados a uma tecnologia de governo de um currículo-EMC - focalizando em aspectos relacionados a um tipo de conteúdo. Entendemos que esse currículo é constituído por "um conjunto de enunciados, na medida em que se apoiem na mesma formação discursiva [...] é constituído de um número limitado de enunciados para os quais podemos definir um conjunto de condições de existência" (FOUCAULT, 2008, p. 132-133).

O enunciado, nessa perspectiva, é uma regularidade (FOUCAULT, 2008; DELEUZE, 2017) que faz com que um conjunto de enunciações possam ser proferidas. Dizer que o enunciado possui uma regularidade é entender que ela é definida pela formação discursiva da própria EMC. Essa regularidade caracteriza o que podemos chamar de prática discursiva em uma dispersão material, isto é, um conjunto de regras discursivas pertencentes ao próprio discurso. Nesse sentido, descrever um discurso como a formação discursiva da EMC, por exemplo, só se faz possível quando levamos em consideração tais regras discursivas. É isso que buscamos realizar ao longo deste artigo.

Cabe destacar que enunciado e enunciações são de níveis diferentes, na medida em que o próprio enunciado não pode ser confundido com a enunciação (FOUCAULT, 2008). Haverá "enunciação cada vez que um conjunto de signos for emitido" (FOUCAULT, 2008, p. 114) nos textos que analisamos. Dessa forma, "a enunciação é um acontecimento que não se repete; tem uma singularidade situada e datada que não se pode reduzir" (FOUCAULT, 2008, p. 114). Já o enunciado é repetível, apesar de sua materialidade (FOUCAULT, 2008). Isso significa dizer que é por meio de um conjunto de enunciações que se constrói um enunciado. Entretanto, este pode ser repetível, aquelas, não.

O enunciado, assumido como regularidade, está para além de palavras, frases ou proposições. Seria o que daria condição para a constituição destas unidades. Nesse sentido, um enunciado está relacionado a todo um conjunto de práticas discursivas.

Para escolhermos os textos que compuseram a pesquisa levamos em consideração o lugar de legitimidade tanto das revistas da educação matemática (Bolema, Zetetiké e Revista Paranaense de Educação Matemática-RPEM) quanto do Encontro Nacional de Educação Matemática, edições de 2010, 2013 e 2016. Esses lugares de legitimidade têm a ver com uma "economia política" (FOUCAULT, 2017, p. 52) de produção da verdade da época considerada sobre a Educação Matemática Crítica, uma vez que

[i] a 'verdade' é centrada na forma do discurso científico e nas instituições que o produzem; [ii] está submetida a uma constante incitação econômica e política (necessidade de verdade tanto para a produção econômica, quanto para o poder político); [iii] é objeto, de várias formas, de uma imensa difusão e de um imenso consumo (circula nos aparelhos de educação ou de informação, cuja extensão no corpo social é relativamente grande, não obstante algumas limitações rigorosas); [iv] é produzida e transmitida sob o controle, não exclusivo, mas dominante, de alguns grandes aparelhos políticos ou econômicos (universidade, exército, escritura, meios de comunicação); enfim, [v] é objeto de debate político e de confronto social (as lutas 'ideológicas') (FOUCAULT, 2017, p. 52). 
Diante disso, os textos em questão estão relacionados, em alguma medida, com as características apresentadas anteriormente, pois são discursos de caráter científico e se relacionam a instituições, como, por exemplo, a Sociedade Brasileira de Educação Matemática e Universidades. São produzidos e transmitidos sob algum controle. Podem ser considerados objetos de debate dentro do campo da educação matemática. Nessa compreensão, assumimos que os periódicos e os Anais do Encontro Nacional de Educação Matemática são lugares que fazem o que podemos chamar de uma economia dos discursos considerados verdadeiros em seu tempo. São lugares de dispersão do discurso que possuem um status de cientificidade, ligado a um suporte institucional. Contudo, e o mais importante para nós, é que essa "verdade" produzida nesses lugares de legitimidade possui relação com o poder, ou melhor, com relações de poder, pois

o poder não reprime, ou reprime apenas secundariamente. O que o poder faz? Faz alguma coisa muito mais profunda e sem dúvida muito mais terrível do que a repressão: ele forma, ele molda [façonne]; ele não faz calar, mas pior: faz falar. Ele disciplina, ele normaliza. A repressão é totalmente secundária com relação às operações positivas do poder. 0 poder não reprime, ele disciplina, ele gere, controla, normaliza etc. Ele não faz calar, faz falar. Ele não impede de agir, ele faz agir (DELEUZE, 2017, p. 13, grifo nosso).

Diante disso, compreendemos que poder e saber se retroalimentam, são complementares, embora em níveis diferentes. Por isso, as produções do Encontro Nacional de Educação Matemática e das revistas foram escolhidas: elas fazem falar e, justamente, por causa disso são consideradas focos de poder para a constituição do corpus composto neste estudo. Em uma perspectiva foucaultiana, ao constituirmos nosso material de análise, é fundamental estarmos atentos aos focos de poder, ou como nas palavras de Deleuze

Para formar um corpus sobre a sexualidade no século XIX, é preciso voltar-se para algo que não é uma palavra, uma frase ou o que for. Não é tampouco um enunciado, já que procuramos saber o que é um enunciado. Bem, a resposta de Foucault, quando a obtém, para dizê-la brutalmente, será: é necessário fixar os focos de poder que produzem tais frases, em torno das quais as palavras, as frases e as proposições se organizam (2017, p. 20, grifo nosso).

É a partir desse corpus de textos referentes à EMC, "corpus especializado" (DELEUZE, 2017, p. 25, grifo do autor), que extraimos o enunciado descrito neste artigo. O corpus, em si, pode ser composto de frase, palavras, proposições e atos de fala. Com esse entedendimento, foram escolhidos 94 textos, a partir de critérios ${ }^{6}$ estabelecidos previamente, que julgamos ser pertencentes à EMC. Lemos cada texto, pelo menos duas vezes, utilizando o software Atlas.ti, que nos auxiliou na construção e no processo de análise. Segue uma rede construída ao longo do processo analítico, com o auxílio do referido software.

\footnotetext{
${ }^{6}$ Para escolher os artigos, como material de análise, estabelecemos como critérios que os textos deveriam conter a expressão "Educação Matemática Crítica" no título e/ou resumo e/ou palavras-chave. Também, procuramos textos que continham a expressão "Skovsmose" ao longo de seu desenvolvimento, visto que este pesquisador é um dos principais representantes da Educação Matemática Crítica no contexto brasileiro e, até mesmo, mundial.
} 


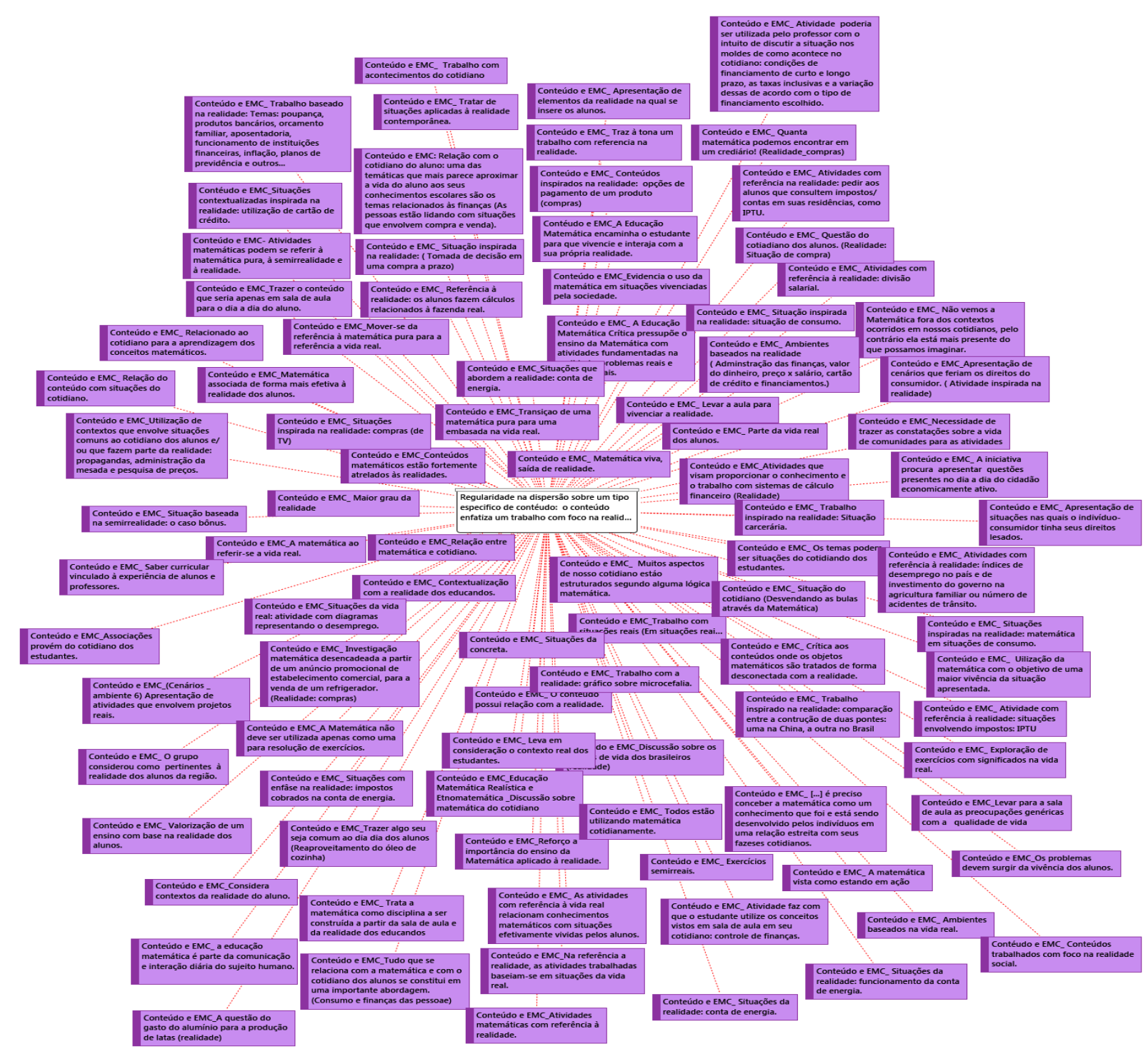

Figura 1 - rede obtida pelo software na construção do enunciado.

Fonte: autores.

Como é possível perceber, a partir da rede apresentada anteriormente, o software facilita o trabalho de análise com uma grande quantidade de dados. É uma ferramenta que auxilia o processo de construção de significados em relação aos dados sob análise. Vale ressaltar que o software não realiza as análises dos dados sozinho, pois todo processo requer que o pesquisador esteja produzindo significados, que não são estáveis e podem mudar de acordo com os dados.

Além disso, o software ajuda a apresentar as informações de forma prática e articulada, como exemplificamos com apresentação da rede anterior. Nessa rede, mostramos como fomos construindo o enunciado deste artigo, por meio da observação de várias enunciações que se associavam.

A rede em questão foi produzida e é resultado de várias etapas do trabalho analítico realizado, visto que este foi se afunilando ao longo do caminho na construção do enunciado. A partir dela, é possível perceber que buscamos uma regularidade na dispersão dos textos por meio de enunciações que se relacionavam, a fim de que fosse possível afirmarmos que tínhamos um enunciado. 


\section{Enunciado sobre conteúdo: conteúdo enfatiza um trabalho com foco na realidade dos estudantes, destacando problemas relevantes e interessantes que abordam questões sociais}

$\mathrm{Na}$ composição deste enunciado, uma primeira regra discursiva relacionada ao conteúdo é que esse precisa possuir um foco na realidade dos estudantes. Vejamos exemplos de marcas discursivas encontradas nos textos:

Diferentes tipos de referenda são possíveis. Primeiro, questões e atividades matemáticas podem se referir à matemática e somente a ela. Segundo, é possível se referir a uma semirealidade - não se trata de uma realidade que "de fato" observamos, mas uma realidade construída, por exemplo, por um autor de um livro didático de matemática. Finalmente, alunos e professores podem trabalhar com tarefas com referências a situações da vida real. (SKOVSMOSE, 2000, p. 7-8, grifo nosso).

A Educação Matemática Crítica pressupõe o ensino da Matemática com atividades fundamentadas na realidade, problemas reais e modelos reais. Quanto às atividades desenvolvidas em um contexto de semirealidade e os exercícios característicos da Matemática Pura, são entendidos como úteis à consolidação do conhecimento, ou seja, poderiam ser utilizados depois da fase inicial de construção do saber, para um reforço na análise dos procedimentos matemáticos.

(BENNEMANN; ALLEVATO, 2013, p. 3, grifo nosso)

$* * *$

Skovsmose (2001) enfatiza que "[...] o problema deve ser concebido como relevante na perspectiva dos estudantes" (SKOVSMOSE, 2001, p.19). Corroborando o que enfatiza o autor, em relação às concepções presentes nos fragmentos, entende-se que tais temas podem ser, por exemplo, situações do cotidiano dos estudantes, sejam situações de suas comunidades ou até mesmo situações reais de um contexto político, social, econômico, entre outros contextos reais pertinentes à estruturação de uma sociedade. Esses, por sua vez, devem ou podem partir de sugestões dos estudantes para que se sintam motivados a aprender $e$ a buscar $o$ conhecimento.

(MESQUITA; CEOLIM, 2017, p. 297, grifo nosso).

A Educação Matemática Crítica (EMC), que encontra em Skovsmose (2000a, 2000b, 2001) um de seus principais representantes, apresenta um contraponto interessante às perspectivas tradicionais em educação matemática, por introduzir, nas aulas de matemática, propostas interdisciplinares que se pautam, inclusive, pela defesa do paradigma de construção de cenários para investigação, abordagem calcada na mudança do paradigma do exercício para o paradigma da investigação. $\underline{A}$ EMC, na perspectiva do autor, pressupõe uma transição da fundamentação na matemática pura para o embasamento na vida real, o que pode dar margem a reflexões sobre a matemática e sobre suas aplicações. Essa transição pode estimular a reflexão dos alunos e conceder à EM uma dimensão crítica.

(HOFMANN; MORO, 2012, p. 39, grifo nosso).

Como se vê, a partir da regularidade das enunciações de um currículo-EMC, o conteúdo matemático precisa enfatizar um trabalho com base na realidade dos estudantes. Ao construir uma forma de pensar sobre o conteúdo, um currículo-EMC mobiliza como regra discursiva na materialidade analisada que alunos e professores podem trabalhar com tarefas com referências a situações da vida real, isto é, atividades fundamentadas na realidade, problemas 
reais e modelos reais ${ }^{7}$. Discursivamente, um currículo-EMC não despreza situações que se referem à matemática pura ou à semirrealidade, pois são entendidas como úteis à consolidação do conhecimento, podendo ser utilizados depois da fase inicial de construção do saber. Na materialidade, um foco na realidade, como elemento de uma prática discursiva, pode ser pensado a partir de um problema que deve ser relevante na perspectiva dos estudantes. Dessa forma, um problema em um currículo-EMC pode estar relacionado a temas como, por exemplo, situações do cotidiano dos estudantes, sejam situações de suas comunidades ou até mesmo situações reais de um contexto político, social, econômico, entre outros contextos reais pertinentes à estruturação de uma sociedade. No currículo-EMC, é proposto que tais temas devem ou podem partir de sugestões dos estudantes para que se sintam motivados a aprender e a buscar o conhecimento. Esse currículo se contrapõe ao ensino tradicional ao propor uma transição da fundamentação na matemática pura para o embasamento na vida real, o que pode dar margem a reflexões sobre a matemática e sobre suas aplicações, podendo estimular a reflexão dos alunos e conceder à EM uma dimensão crítica.

Chegamos à segunda regra discursiva que um currículo-EMC, ao construir uma maneira de se pensar os conteúdos, propõe na discursividade, ou seja, além de os conteúdos possuírem um foco na realidade dos estudantes, é preciso também pensar em problemas relevantes e interessantes que abordam questões sociais. Vamos às marcas discursivas:

O pensamento de Educação Crítica de Paulo Freire é incorporado por Skovsmose (2001, p.101), ao realizar seus estudos sobre a Educação Matemática Crítica: "[...] para que a educação, tanto como prática quanto como pesquisa, seja crítica, ela deve estar a par dos problemas sociais, das desigualdades, [...] e deve tentar fazer da educação uma força social progressivamente ativa [...]. Para ser crítica, a educação deve reagir às contradições sociais". Para o autor, na Educação Matemática Crítica, o processo educacional não pode estar desvinculado da comunidade escolar. Ao contrário, deve relacionar-se com problemas encontrados em situações do cotidiano do aluno.

(CAMPOS et al., 2011, p. 476, grifo nosso).

O que a educação matemática crítica propõe é um novo paradigma: é possível desenvolver no aluno a capacidade de gerenciamento das questões que se lhe apresentem? É possível desenvolver no estudante a capacidade crítica que possibilitará a paulatina construção de sua autonomia? Uma estratégia que pode ser usada na educação crítica é a tematização. Buscase um problema de relevância para os alunos, ligado às suas experiências.

(TEIXEIRA; COUTINHO, 2013, p. 10, grifo nosso).

É possivel perceber que os alunos ficam passivos no processo educativo quando o conteúdo é ministrado de maneira descontextualizada e metódica. Sem levar em consideração os saberes vivenciados pelos alunos em suas práticas diárias, bem como as suas vontades presentes $e$ futuras, o ensino de matemática geralmente torna-se desinteressante.

(REIS; FERREIRA, 2010, p. 8, grifo nosso).

\footnotetext{
${ }^{7}$ Essas partes, em itálico, são enunciações que fazem parte dos excertos que estamos analisando, e, para facilitar o processo de composição do que viria a ser um currículo-EMC, procurou-se apresenta-las dessa forma, ao invés de colocar aspas e as referências novamente. É um procedimento que adotamos e que potencializou nossas análises: ao expor essas frases ou trechos juntos, há uma composição de um sentido que estaria em uma determinada direção que, para nós, seria a de um currículo-EMC.
} 
Compreender as relações entre os saberes e fazeres matemáticos que permeiam o contexto escolar e a realidade do grupo envolvido na pesquisa à luz da dimensão educacional da Etnomatemática e da Educação Matemática Crítica implica dialogar com a cultura dos indivíduos envolvidos no processo educativo valorizando e problematizando criticamente $o$ contexto social, político, econômico no qual estão inseridos.

(REIS; FERREIRA, 2010, p. 1, grifo nosso).

Vê-se que na materialidade o conteúdo, além de possuir um foco na realidade, também precisa ser pensado a partir de problemas (sociais). Assim, na prática discursiva de um currículo-EMC, o processo educacional não pode estar desvinculado da comunidade escolar dos estudantes, mas relacionado aos problemas encontrados em situações do cotidiano do aluno. Ao construir uma maneira de pensar e propor os conteúdos, um currículoEMC considera importante ultrapassar os limites da sala de aula, ao convidar o estudante a refletir sobre problemas do seu dia-a-dia (FILHO; FAUSTINO; MOURA, 2017, p. 65, grifo nosso).

Entretanto, tais problemas precisam ser relevantes e interessantes do ponto de vista da experiência dos estudantes. Por isso, a escolha das atividades se baseia em sua relevância no contexto sociopolítico dos alunos (BENNEMANN; ALLEVATO, 2013, p. 5, grifo nosso), buscando problemas ligados às suas experiências. Em termos de interesse, um currículo-EMC leva em consideração os saberes vivenciados pelos alunos em suas práticas diárias, bem como as suas vontades presentes e futuras, para que o ensino de matemática não se torne desinteressante. Por isso, a importância, na prática discursiva destacada na materialidade, de os conteúdos abordarem questões sociais. De acordo com um currículo-EMC, pensar os conteúdos levando em consideração questões sociais estaria relacionado em dialogar com $a$ cultura dos indivíduos envolvidos no processo educativo valorizando e problematizando criticamente o contexto social, político e econômico.

Até este ponto, descrevemos regras de formações comuns da superfície discursiva que nos permitiram construir o enunciado sob análise. No entanto, em uma perspectiva foucaultiana, para além de construir o objeto "conteúdo" de maneira discursiva, um currículoEMC coloca em movimentos relações de poder-saber.

Na sequência, procuramos fazer uma discussão mais detalhada sobre isso.

\section{Um pensar outro, a partir do enunciado produzido: construção de uma tecnologia de governo}

A partir do enunciado construído, isto é, o conteúdo enfatiza um trabalho com foco na realidade dos estudantes, destacando problemas relevantes e interessantes que abordam questões sociais, podemos destacar que um currículo-EMC não possui um desde sempre aí, pois se trata de algo que é fundamentalmente histórico.

Diante disso, por um lado, esse currículo é herdeiro de regimes de verdade referente, principalmente, à Educação Crítica. Integra um regime que busca se distanciar de um ensino tradicional e a-político, fazendo parte de uma virada sociopolítica ${ }^{8}$ dentro da própria educação matemática. Dessa maneira, podemos afirmar que esse currículo está inserido em um jogo discursivo que possui relação com o pensamento de Paulo Freire e com os estudos desenvolvidos por pesquisadores da escola de Frankfurt.

\footnotetext{
${ }^{8}$ Ver sobre isso trabalhos, por exemplo, de Paola Valero $(2008,2010)$ e Marcio Antonio da Silva e Roger MiarKa
} (2017). 
Por outro lado, ao produzir, na discursividade, um tipo de conteúdo focado na realidade dos estudantes e em uma abordagem investigativa (Esta abordagem foi discutida por nós em outro lugar), a fim de que se obtenha uma aprendizagem mais contextualizada ${ }^{9}$, isto é, ao tratar de temas da realidade, um currículo-EMC é atravessado e pode ser associado a um modo de pensar e praticar a educação que teve início, mais ou menos, nos alvores do século XX, período que marca o "estabelecimento das bases conceituais do que conhecemos como sociedade da aprendizagem" (MARÍN-DÍAZ; NOGUERA-RAMÍREZ, 2014, p. 53).

Nessa sociedade, a forma subjetiva privilegiada é a do Homo discens, isto é, aquele indivíduo que é um aprendente, mas que não só deve aprender, mas aprender a aprender. Nesse sentido, poderíamos dizer que em um currículo-EMC um aprender a aprender estaria ligado principalmente às questões da realidade por meio de investigações que seriam desenvolvidas pelos próprios estudantes. Vamos a algumas marcas:

Mover-se do paradigma do exercício em direção ao cenário para investigação [que se baseia, principalmente, em situações reais] pode contribuir para o enfraquecimento da autoridade da sala de aula tradicional de matemática e engajar os alunos ativamente em seus processos de aprendizagem.

(SKOVSMOSE, 2000, p. 1, grifo nosso).

À Educação Matemática Crítica atribui-se uma competência democrática e reflexiva: os alunos assumem o papel de participantes de uma aprendizagem voltada para a compreensão e leitura do mundo baseadas em experiências que consideram interessantes e relevantes ao processo educativo.

(PAGUNG; REZENDE; LORENZONI, 2016, p. 1, grifo nosso).

Em um cenário para a investigação [que se baseia, principalmente, em situações reais], a aprendizagem tende a acontecer como um convite ao conhecimento, momento propício para que os estudantes busquem por soluções ou elaborem questionamentos.

(BRITTO et al. 2017, p. 375, grifo nosso).

O estudante, em um currículo-EMC, não é um mero receptor de conhecimentos matemáticos quando tratamos de seu processo de aprendizagem. Entretanto, o que queremos argumentar, a partir de um texto de Marín-Díaz e Noguera-Ramírez (2014) que nos apresenta algumas ideias de um estudo realizado por Noguera-Ramírez (2011), é o fato de que a educação pode ser assumida como uma das artes de governo desde o começo do século XVI. Nessa arte, é possível perceber três modos de pensar e praticar a educação e o ensino para os quais há formas específicas de subjetividades privilegiadas. No primeiro modo, temos

${ }^{9}$ Vejamos apenas dois exemplos de enunciações relacionados a isso:

(i) “Objetiva-se, portanto, buscar significados para uma efetiva aprendizagem da Matemática por meio de atividades contextualizadas na realidade sociocultural dos alunos, bem como em seus interesses" (REIS; FERREIRA, 2010, p. 3 grifo nosso).

(ii) "Considerando o significado da aprendizagem como relacionado mais ao futuro que ao passado, enfatiza que o sentido de escolaridade dos estudantes, em geral, e de educação matemática, em particular, não é apenas cognitivo por natureza, mas também sócio-político. O significado dado à aprendizagem está ligado às condições sociais, políticas, culturais e econômicas do aprendiz e como ele as interpreta" (SKOVSMOSE, 2012, p. 235, grifo nosso). 
o Homo docilis - uma pessoa dócil, que é capaz de aprender e de ser ensinada, no segundo, o Homo civilis - uma pessoa civilizável e, no terceiro modo de se pensar e praticar a educação, a subjetividade se relaciona ao Homo discens - um indivíduo que é um aprendiz, mas que não só deve aprender, mas é preciso aprender a aprender. Portanto, ao dar ênfase em uma aprendizagem que precisa ser contextualizada e que possui os estudantes como protagonistas, valorizando não só os aspectos direcionados ao ensino, um currículo-EMC estaria mais associado a esse terceiro tipo de pensar e propor a educação.

Uma questão que é muito específica em um currículo-EMC, quando se trata de aprendizagem e conteúdos pensados a partir da realidade, é o fato de que tal aprendizagem precisa preparar os estudantes para atuação de forma cidadã. Vejamos:

Neste contexto, o significado da aprendizagem matemática ultrapassa os muros de uma definição e pode ser compreendido como a atuação que prepara os estudantes na promoção da cidadania. Alrø e Skovsmose (2010, p.140) admitem que 'aprender pode significar aprender para a cidadania; e cidadania exige competências que são importantes para uma pessoa participar da vida democrática e para desenvolver a cidadania crítica'.

(BRITTO et al. 2017, p. 375, grifo nosso)

Diante de uma aprendizagem voltada para a cidadania crítica, algo fundamental quando se pensa em um currículo-EMC, a partir do enunciado que construímos, é sua a compreensão sobre a realidade que, nesse currículo, não pode ser qualquer uma, mas precisa estar direcionada a problemas em âmbito coletivo e que os estudantes assumam esses problemas como seus. Vejamos:

Para isso, é importante que eles [estudantes] vivenciem situações problemáticas reais e que reconheçam esses problemas como seus:

'[...] é essencial que os problemas se relacionem com situações e conflitos sociais fundamentais, e é importante que os estudantes possam reconhecer os problemas como 'seus próprios problemas' [...]. Problemas não devem pertencer a 'realidades de faz-de-conta' sem nenhuma significação' [...]. (SKOVSMOSE, 2001, p. 24).

(VELEDA; ESTEVAM, 2013, p. 3, grifo nosso).

Uma das preocupações da Educação Matemática Crítica é discutir os ambientes de aprendizagem em sala de aula. Tais discussões incluem a importância de ultrapassar os limites da sala de aula, de convidar o estudante a refletir sobre problemas do seu dia-a-dia, de proporcionar um espaço para questionar a realidade social, cultural, política e econômica, de incentivar os estudantes a uma reflexão que os estimulem a atuarem no meio em que vivem. (FILHO; FAUSTINO; MOURA, 2017, p. 65, grifo nosso).

Ao incentivar os sujeitos a refletirem sobre os problemas sociais a sua volta, propiciamos aos mesmos a possibilidade de perceberem o quanto estão inseridos nesse contexto. Através das aulas de matemática podemos ajudá-los nesse processo.

(NEVES; SANTOS; GUERRA, 2010, p. 5, grifo nosso)

$* * *$

Dessa forma, poderão surgir, durante as resoluções das atividades, uma pesquisa empírica ou um projeto de intervenção, a depender da questão trabalhada. O debate neste caso é direcionado para a mudança social. Assim, será possivel trabalhar os conteúdos matemáticos em plena articulação com as dimensões sociais, políticas, econômicas e culturais e, ainda, aprofundar os conceitos da própria matemática.

(MILANI et al. 2017, p. 239, grifo nosso). 
Assim, uma realidade, de um currículo-EMC, não é qualquer realidade. Não se trata de qualquer cotidiano, mas de algo que é comum e de interesse público. Trata-se de algo problemático observado no social e que precisa ser compreendido e resolvido pelas pessoas, podendo, com isso, gerar uma mudança social.

Uma outra questão a ser destacada é o modo que um currículo-EMC pode estabelecer suas relações de poder no campo da educação matemática quando concebemos um tipo de conteúdo, proposto a partir do enunciado que diz que o conteúdo enfatiza um trabalho com foco na realidade dos estudantes, destacando problemas relevantes e interessantes que abordam questões sociais.

Nesse sentido, um currículo-EMC para produzir possíveis subjetividades desejáveis (um professor desejável e um aluno desejável), dentro da educação matemática, cria sua própria tecnologia de governo, isto é, um campo tecnológico que se coloca a operar para reforçar seu próprio discurso. Uma tecnologia de um currículo-EMC seria a construção de um espaço que procura entrelaçar relações de poder com o saber sobre o campo da educação matemática.

Tal tecnologia é composta por técnicas e procedimentos, como afirma Castro (2009), ao retomar o pensamento de Foucault, "estes mecanismos do poder, estes procedimentos de poder, há que se considerá-los como técnicas, isto é, como procedimentos que foram inventados, aperfeiçoados, que se desenvolveram sem cessar. Existe uma verdadeira tecnologia do poder ou, melhor, dos poderes, que têm sua própria história" (CASTRO, 2009, p. 412).

Desse modo, ao tratar um currículo-EMC como uma forma de saber que pode estabelecer suas relações de poder no campo da educação matemática, podemos afirmar que o enunciado produzido está relacionado a essas técnicas, com seus respectivos procedimentos que colaboram, em certa medida, para a constituição de determinadas posições de sujeitos desejáveis por meio de uma tecnologia de governo que se coloca a operar ao se pensar um tipo de conteúdo específico com base na realidade (isso, a nosso ver, também é válido para um tipo de ensino constituído por um currículo-EMC).

Sendo assim, em termos de constituição de um tipo específico de conteúdo, considerando o enunciado construído, concebemos que há uma técnica mobilizada em um currículo-EMC a respeito de como deve ser abordado o conteúdo, a saber, técnica de trabalhar o conteúdo com foco na realidade dos estudantes. Essa técnica faz funcionar um procedimento de que os problemas precisam ser relevantes, interessantes e abordem questões sociais. Tais técnicas e seus respectivos procedimentos reforçam o próprio discurso de um currículo-EMC dentro do campo da educação matemática. Portanto, em uma tecnologia de governo de um currículo-EMC, técnicas e procedimentos se articulam, buscando produzir um modo desejável de ser estudante e de ser professor dentro da educação matemática.

Um trabalho com um conteúdo pensado a partir da realidade, ou melhor, ao colocar uma técnica de trabalhar o conteúdo com foco na realidade dos estudantes em operação, um currículo-EMC faz funcionar uma prática não coercitiva, mas que coloca e mantém os estudantes em um jogo pedagógico estratégico para a produção de sujeitos - um sujeito resolvedor de problemas e, justamente, por isso este poderá se tornar um "cidadão-críticoconsciente-ativo" na sociedade (OLIVEIRA; SILVA, M.A., 2019b). Dessa forma, a técnica de um currículo-EMC, em tela, estabelece uma relação de poder que se articula sobre dois elementos indispensáveis: "que 'o outro' (aquele sobre o qual ela se exerce) seja inteiramente reconhecido e mantido até o fim como o sujeito de ação; e que se abra, diante da relação de 
poder, todo um campo de respostas, reações, efeitos, invenções possíveis" (FOUCAULT, 1995, p. 243). Como ilustração, vejamos um exemplo:

Na perspectiva de Skovsmose, pesquisa e investigação apontam maneiras pelas quais a aprendizagem pode acontecer como ação, nesse viés podemos convidar, mas nunca impor aos alunos a participação de atividades em torno de um cenário de investigação [que se baseia, principalmente, em situações reais]. Se irão aceitar ou não é sempre uma incógnita. Eles poderão ficar fascinados com a proposta ou não manifestar nenhum interesse, uma vez que existem muitos fatores envolvidos nesse processo.

(ALMEIDA; SOUZA, 2017, p. 310, grifo nosso).

Uma técnica de trabalhar o conteúdo com foco na realidade dos estudantes associada a uma técnica que se relaciona ao ensino, em um currículo-EMC, não busca a coerção, mas um processo de autoformação, uma vez que essas técnicas "permitem aos indivíduos efetuarem um certo número de operações sobre os seus corpos, sobre as suas almas, sobre o seu próprio pensamento, sobre a sua própria conduta, e isso de tal maneira a transformaremse a eles próprios, a modificarem-se" (FOUCAULT, 1993, p. 207, grifo nosso), a fim de que sejam produzidas as subjetividades desejáveis em um currículo-EMC, considerando situações problemáticas que sejam coletivas e reais.

Diante disso, ao estabelecer as regras discursivas analisadas, um currículo-EMC busca por meio de um conteúdo com foco na realidade dos estudantes e compreendido como técnica, que os sujeitos sejam produzidos de maneira ativa por intermédio de práticas de si advindas de um contexto real, isto é, é preciso tanto que professores e estudantes resolvam problemas que sejam coletivos e não individualizados, participem ativamente e dialoguem, sempre recorrendo a situações da realidade que sejam relevantes, interessantes e que abordem questões sociais. Assim, um currículo-EMC, por meio do enunciado sob análise, está mais preocupado com questões de âmbito coletivo. Daí a própria aprendizagem, a partir de conteúdos com foco na realidade dos estudantes, ser concebida como um coletivo de pessoas em um currículo-EMC.

Como explicitado acima, o trabalho de campo está sendo desenvolvido em duas salas de aula, um ambiente complexo, que abrange conflitos, interações, onde o processo de conhecer é vivenciado por um grupo de seres humanos, e não por um único indivíduo, portanto concebemos o sujeito de aprendizagem como o grupo de alunos e alunas, o que justifica nossa aproximação de epistemologias dialógicas e o afastamento de epistemologias monológicas: 'A epistemologia genética de Piaget é um caso de epistemologia monológica, como também é o construtivismo radical como apresentado por Glasersfeld. Contudo podemos pensar em um grupo de pessoas, ao invés de uma pessoa individual, como sendo o 'sujeito que aprende'. (...) Podemos ver o sujeito da aprendizagem como parte de uma rede, que inclui seres humanos $e$ elementos não-humanos. $O$ sujeito da aprendizagem pode então ser definido em termos de relacionamento interpessoal, bem como em termos de relações humano-tecnológicas. $O$ sujeito da aprendizagem torna-se unidade relacional' (SKOVSMOSE, 2007, p. 229).

(FAUSTINO, 2013, p. 2, grifo nosso).

A partir do que foi exposto até aqui, podemos afirmar que o enunciado em tela, na busca de conduzir a conduta de professores e estudantes em direção a um trabalho dos conteúdos com foco na realidade, está relacionado aos "jogos estratégicos entre as liberdades" na educação matemática (FOUCAULT, 2004a, p. 285) que foram mobilizados na materialidade analisada. 
Diante disso, um tipo de conteúdo produzido na discursividade de um currículo-EMC, por meio do enunciado construído, pode ser compreendido como técnica estratégica que compõe uma tecnologia de governo estabelecida por esse próprio currículo, a fim de que seja produzido tipos humanos (professores e alunos) dentro da educação matemática.

Um currículo-EMC, por meio da técnica aqui analisada, procura convencer os estudantes de que eles não são forçados a fazer as coisas. Assim, um currículo-EMC não "impõe" os conteúdos, uma vez que estes estão relacionados à realidade e por isso ele incita os alunos a terem curiosidade, a buscarem problemas do dia a dia para serem estudados em sala, buscando responsabilizá-los pela construção do processo e na condução da atividade.

A condição para o estabelecimento das relações de poder de um currículo só é possível em meio a liberdade dos indivíduos. Diante disso, um currículo-EMC, ao colocar em operação uma tecnologia para a transformação dos seres humanos em sujeitos de determinado modo, busca trabalhar com suas liberdades. Nesse currículo, pretende-se governar indivíduos livres e autônomos acima de tudo. Com isso, podemos afirmar que uma tecnologia de governo de um currículo-EMC propõe um modo de governar sem governar ${ }^{10}$ (RAMOS DO Ó, 2009), tanto por meio de uma técnica pensada para sobre o ensino (que não é o foco da nossa análise neste momento), quanto como uma técnica relacionada ao conteúdo (estudantes buscam problemas que consideram suas realidades).

Uma tecnologia de governo de um currículo-EMC, por meio da técnica de trabalhar o conteúdo com foco na realidade dos estudantes, propõe um ensino de matemática que busca realizar a fabricação de um possível tipo de estudante resolvedor de problemas (POPKEWITZ, 2004) que estejam pautados na realidade, a fim de que tais problemas não sejam sem sentido ou desinteressantes. Assim, essa técnica procura estabelecer relações de poder sutis, por meio do uso da realidade, para que os próprios estudantes sejam inseridos em um contexto em que a própria matemática adquire status de ciência legitimada e reconhecida como capaz de tratar dos problemas da realidade.

Compreendemos que isso reforça o lugar privilegiado que é atribuído à própria matemática escolar (QUARTIERI, 2012) como ciência que é capaz de lidar como os problemas da realidade, modelando-os, apresentando soluções e embasando a tomada de decisões. Por meio da técnica em questão, é possível aos estudantes - sujeitos livres, autônomos e democráticos, como propõe a prática discursiva de um currículo-EMC - apresentar problemas coletivos de sua realidade e que sejam interessantes. Dessa forma, a liberdade que é conferida ao estudante para escolha de temas de sua realidade e de seu interesse pode, também, ser entendida como uma maneira do próprio docente procurar controlar as ações (QUARTIERI, 2012) do processo educacional sem controlar, buscando conduzir a conduta dos estudantes, transformando-os em alguém corresponsável por sua própria aprendizagem e que se interesse pela matemática escolar, bem como por sua legitimidade.

Há muitas implicações que são defendidas por uma prática discursiva de um currículoEMC para se pensar a matemática com foco na realidade, dentre elas, podemos dizer que se

\footnotetext{
${ }^{10}$ Isso reforça a ideia de que um currículo-EMC está para além das técnicas de dominação, aproximando-se das técnicas de si. Ao apresentarmos essa expressão extraída dos estudos de Ramos do Ó (2009, queremos enfatizar a maneira pela qual um currículo-EMC, por meio do enunciado analisado, neste texto, tomado como técnica, recorre "a processos pelos quais o indivíduo age sobre si próprio" (FOUCAULT, 1993, p. 207). A sutileza de um currículo-EMC ao colocar em funcionamento suas relações de poder não está nas técnicas de dominação, mas nas técnicas de si. Os indivíduos, ao tratar de temas da sua realidade, pensam que estão agindo livremente, por isso, esse currículo-EMC busca um modo de governar sem governar.
} 
busca, em primeiro lugar, um rompimento com a ideia de uma matemática infalível, dando as costas, desse modo, a uma ideologia da certeza. Outro argumento é o de que por meio desse trabalho é possível formar sujeitos mais críticos e atuantes na sociedade.

Contudo, ao se pensar essa técnica por meio de uma abordagem contemporânea, ainda que os conteúdos sejam trabalhados na pretensão de se trazer a realidade dos alunos para a sala de aula, um currículo-EMC faz parte de um jogo de linguagem (WITTGENSTEIN, 1999) da matemática como prática social. Dito de outro modo, a matemática que é trabalhada no ambiente escolar não é de fato a da realidade, mas possui semelhança de família (WITTGENSTEIN, 1999) com a matemática de uma realidade fora da escola. Isso significa que são coisas diferentes, operam de formas diferentes por meio de relações de poder também distintas. Mas, por meio de uma alquimia (POPKEWITZ, 2004), a matemática escolar é transformada em uma matemática da realidade fora da escola, como se os conteúdos fossem realmente reais. Eles podem ser reais do ponto de vista dos dados, mas o contexto no qual estão operando está relacionado à escola. Por isso, a ideia de semelhança de família. Nessa perspectiva, ainda que um estudante, por meio de um currículo-EMC, aprenda tudo sobre cartão de crédito no ambiente escolar, sobre como consumir de forma consciente para evitar o problema social do endividamento familiar, por exemplo, como propõe alguns trabalhos analisados, abordando juros e taxas, essa realidade não é a mesma quando este estudante sai para comprar um videogame, por exemplo.

Nessa compra, há somente semelhanças de famílias com o tema visto na escola. Outras questões operam nessa situação, quais sejam, o próprio desejo de estar diante do videogame e não querer esperar mais tempo para comprá-lo, assumindo, dessa forma, vários pagamentos no cartão de crédito. Essa realidade a escola não reproduz. Apenas ensina que não é legal se endividar, pois isso pode acarretar em um problema social muito sério. Por isso, a ideia de alquimia, um currículo-EMC realiza uma transformação da matemática escolar em uma matemática da realidade da mesma forma que um aquimista, na Idade Média, procurava transformar pedra em ouro.

\section{Palavras finais}

No decorrer deste artigo, tivemos por objetivo analisar uma tecnologia de governo evocada para a efetivação de possíveis posições de sujeito em um currículo-EMC. Nesse sentido, discutimos como esse currículo estabelece suas relações de poder dentro da educação matemática a partir de um enunciado construído ao longo das análises: o conteúdo enfatiza um trabalho com foco na realidade dos estudantes, destacando problemas relevantes e interessantes que abordam questões sociais.

Foi apresentado, a partir do enunciado em tela, que a realidade em um currículo-EMC não se trata de algo individualizado, mas de problemas - sociais, políticos e econômicos coletivizados. Ao tratar de temáticas da realidade, esse currículo quer colocar professor e estudantes a par de problemáticas sociais que precisam ser compreendidas e resolvidas, podendo, com isso, gerar uma mudança na sociedade.

Um currículo-EMC para produzir possíveis subjetividades desejáveis cria sua própria tecnologia de governo por meio de técnicas e procedimentos que se colocam a operar para reforçar seu próprio discurso dentro do dispositivo da educação matemática. É nesse sentido que consideramos o enunciado, em questão, como uma técnica mobilizada por um currículoEMC a respeito de como deve ser pensado o conteúdo, a saber, técnica de trabalhar o conteúdo com foco na realidade dos estudantes. Essa técnica faz funcionar um procedimento 
de que os problemas precisam ser relevantes, interessantes e abordem questões sociais. Em uma tecnologia de governo de um currículo-EMC, essa técnica se articula ao procedimento apresentado para produzir um modo desejável de ser dentro da educação matemática.

Dessa forma, um currículo-EMC faz funcionar uma prática não coercitiva por meio da técnica aqui apresentada, pois coloca e mantém os estudantes em um jogo pedagógico estratégico para a produção de sujeitos - um sujeito resolvedor de problemas e, justamente, por isso este poderá se tornar um "cidadão-crítico-consciente-ativo" na sociedade (OLIVEIRA; SILVA, M.A., 2019b). Diante disso, um currículo-EMC, por meio do enunciado em questão, na busca de conduzir a conduta de professores e estudantes em direção a um trabalho dos conteúdos com foco na realidade, está relacionado aos "jogos estratégicos entre as liberdades" na educação matemática (FOUCAULT, 2004a, p. 285) que foram mobilizados na materialidade analisada.

Sendo assim, a condição para o estabelecimento das relações de poder de um currículo só é possível em meio a liberdade dos indivíduos, por esse motivo uma tecnologia de governo de um currículo-EMC propõe um modo de governar sem governar (RAMOS DO Ó, 2009). Para isso, uma técnica relacionada à realidade procura estabelecer relações de poder sutis ao usar a própria realidade para que os estudantes sejam inseridos em um contexto em que a própria matemática adquire status de ciência legitimada e reconhecida como capaz de tratar dos problemas da realidade.

\section{Referências}

ALMEIDA, K. F.; SOUZA, R. B. Educação Matemática Crítica e materiais apostilados: perspectivas e concepções de ensino de fração. Revista Paranaense de Educação Matemática, v.6, n.12, p.306-325, 2017.

BAMPI, L. R. Governo etnomatemático: tecnologias do multiculturalismo. 2003. 199f. Tese (Doutorado em Educação) - Universidade Federal do Rio Grande do Sul, Porto Alegre, 2003.

BENNEMANN, M.; ALLEVATO, N. S. G. Uma experiência de formação continuada envolvendo Educação Matemática Crítica e tecnologias de informação e comunicação. In: ENCONTRO NACIONAL DE EDUCAÇÃO MATEMÁTICA, 11, 2013. Curitiba. Anais... Curitiba: Sociedade Brasileira de Educação Matemática, 2013. p. 1-13.

BRITTO, R. R. et al. Cenários para investigações nas salas de aulas de matemática de escolas brasileiras. Revista Paranaense de Educação Matemática, v.6, n.12, p.371-396, 2017.

CAMPOS, C. R. et al. Educação Estatística no Contexto da Educação Crítica. Bolema: Boletim de Educação Matemática, v. 24, n. 39, p. 473-494, 2011.

CASTRO, E. Vocabulário de Foucault: um percurso pelos seus temas, conceitos e autores. Belo Horizonte: Autêntica, 2009.

DELEUZE, G. Michel Foucault: as formações históricas. São Paulo: n-1 edições, 2017.

FILHO, D. B.; FAUSTINO, A. C.; MOURA, A. Q. Cenários para investigação, imaginação e ação. Revista Paranaense de Educação Matemática, v.6, n.12, p.64-80, 2017. 
FOUCAULT, M. A arqueologia do saber. Rio de Janeiro: Forense Universitária, 2008.

FOUCAULT, M. A Ética do Cuidado de Si como prática de liberdade.In: Ditos e escritos, volume V: ética, sexualidade, política. FOUCAULT, Michel. MOTTA, Manoel Barros da (org.). Rio de Janeiro: Forense Universitária, 2004a, p. 264-287.

FOUCAULT, M. Microfísica do Poder. Rio de Janeiro: Paz e Terra, 2017.

FOUCAULT, M. O sujeito e o poder. In: DREYFUS, Hubert; RABINOW, Paul. Michel Foucault. Uma trajetória filosófica: para além do estruturalismo e da hermenêutica. Rio de Janeiro: Forense universitária, 1995, p. 231-249.

FOUCAULT, M. Tecnologias de si, 1982. VERVE: Revista Semestral do NU-SOL - Núcleo de Sociabilidade Libertária/Programa de Estudos Pós-Graduados em Ciências Sociais. Tradução de Andre Degenszajn. n. 6, p. 321-360, 2004b.

FOUCAULT, M. Verdade e subjetividade. Revista de Comunicação e linguagem. Lisboa: Edições Cosmos, n. 19, p. 203-223, 1993.

FOUCAULT, M. Vigiar e Punir: nascimento da prisão. Rio de Janeiro: Vozes, 2014.

HOFMANN, R. M.; MORO, M. L. F. Educação matemática e educação financeira: perspectivas para a ENEF. ZETETIKÉ, v. 20, n. 38, 2012.

MARÍN-DÍAZ, D. L.; NOGUERA-RAMÍREZ, C. E. O efeito educacional em Foucault. O governamento, uma questão pedagógica? Pro-Posições, v. 25, n. 2, p. 47-65, 2014.

MESQUITA, M. N.; CEOLIM, A. J. Modelagem Matemática: abordagens na educação básica na perspectiva da Educação Matemática Crítica. Revista Paranaense de Educação Matemática, v.6, n.12, p.281-305, 2017.

OLIVEIRA, A. A.; SANTOS, L. T. B.; PESSOA, C. A. S. Do exercício aos cenários para investigação: a aplicação de atividades de Educação Financeira por professoras dos anos iniciais do ensino fundamental em uma escola de Recife - PE. Revista Paranaense de Educação Matemática, v.6, n.12, p.158-186, 2017.

OLIVEIRA, J.C.G.O.; SILVA, M. A. O desejável professor de matemática constituído pelo discurso da Educação Matemática Crítica. Revista Paradigma, v. 40, n. 2, p. 31-51, dez. de 2019a.

OLIVEIRA, J.C.G.O.; SILVA, M. A. O estudante desejável constituído pelo discurso da Educação Matemática Crítica. Revista Paranaense de Educação Matemática, v.8, n.17, p.17-44, jul.-dez. 2019b.

PAGUNG, C. M. D.; REZENDE, O. L. T.; LORENZONI, L. L. As contribuições da Modelagem Matemática na construção do conceito de função: análises e discussão de resultados. In: ENCONTRO NACIONAL DE EDUCAÇÃo MATEMÁTICA, 12, 2016. São Paulo. Anais... São Paulo: Sociedade Brasileira de Educação Matemática, 2016. p. 1-12.

POPKEWITZ, T. The alchemy of the mathematics curriculum: Inscriptions and the fabrication of the child. American Educational Research Journal, v. 41, n. 1, p. 3-34, 2004. 
QUARTIERI, MARLI TERESINHA. A Modelagem Matemática na escola básica: a mobilização do interesse do aluno e o privilegiamento da matemática escolar. 2012. 198 f. Tese (Doutorado em Educação) - Universidade do Vale do Rio dos Sinos, São Leopoldo, 2012.

RAMOS DO Ó, J. A governamentalidade e a História da Escola Moderna: outras conexões investigativas. Revista Educação \& Realidade, v. 34, n. 2, p. 97-117, 2009.

REIS, J. F.; FERREIRA, R. Etnomatemática como meio para uma aprendizagem significativa da matemática: contextos pautados na realidade sócio-cultural dos alunos. In: ENCONTRO NACIONAL DE EDUCAÇÃO MATEMÁTICA, 10, 2010. Salvador. Anais... Salvador: Sociedade Brasileira de Educação Matemática, 2010. p. 1-10.

SILVA, M. A. Currículo e Educação Matemática: a política cultural como potencializadora de pesquisas. Perspectivas da Educação Matemática, v. 11, n. 26, p. 1-23, 2018.

SILVA, M. A.; MIARKA, R. Geni, a Pesquisa em [E]educação [M]matemática e o Zepelim. Perspectivas da Educação Matemática, v. 10, n. 24, p. 752-767, 2017.

SKOVSMOSE, O. Cenários para Investigação. Bolema: Boletim de Educação Matemática, v. 13, n. 14, p. 1-24, 2000.

SKOVSMOSE; O. et. al. A Aprendizagem Matemática em uma Posição de Fronteira: foregrounds e intencionalidade de estudantes de uma favela brasileira. Bolema: Boletim de Educação Matemática, v. 26, n. 42, p. 231-260, 2012.

TEIXEIRA, J., COUTINHO, C. Q. S. A educação financeira preconizada pela ENEF - estratégia nacional de educação financeira e seus efeitos na escola básica: uma análise do guia do PNLD. In: ENCONTRO NACIONAL DE EDUCAÇÃO MATEMÁTICA, 11, 2013. Curitiba. Anais... Curitiba: Sociedade Brasileira de Educação Matemática, 2013. p. 1-15.

VALERO, P., Discourses of power in mathematics education research: concepts and possibilities for action. PNA, v. 2, n. 2, p. 43-60, 2008.

VALERO, P.; ANDRADE-MOLINA, M.; MONTECINO, A. Lo políticoen la educación matemática: de la educación matemática crítica a la política cultural de la educación matemática. Revista Latinoamericana de Investigación en Matemática Educativa, v.18, n.3, p. 287-300, 2015.

VALERO, Paola. Mathematics education as a network of social practices. In: Proceedings of the sixth congress of the european society for research in mathematics education, 6., 2009, Lyon. Anais... Lyon: Institut National de Récherche Pédagogique, 2010, p. LIV-LXXX.

VELEDA, G. G.; ESTEVAM, E. J. G. Modelagem Matemática na formação inicial de professores: fomentando a Educação Matemática Crítica a partir das Eleições. In: ENCONTRO NACIONAL DE EDUCAÇÃO MATEMÁTICA, 11, 2013. Curitiba. Anais... Curitiba: Sociedade Brasileira de Educação Matemática, 2013. p. 1-13.

WITTGENSTEIN, L. Investigações Filosóficas. São Paulo: Editora Nova Cultural, 1999. 